\title{
A!
}

This is an electronic reprint of the original article.

This reprint may differ from the original in pagination and typographic detail.

Pietarinen, Heidi; Timonen, Eija

\section{The flying ants and the beauty of ice}

Published in:

Arts-Based Methods for Decolonising Participatory Research

Published: 18/04/2021

Document Version

Publisher's PDF, also known as Version of record

Published under the following license:

CC BY-NC-ND

Please cite the original version:

Pietarinen, H., \& Timonen, E. (2021). The flying ants and the beauty of ice. In Arts-Based Methods for Decolonising Participatory Research (pp. 198-216). Routledge.

This material is protected by copyright and other intellectual property rights, and duplication or sale of all or part of any of the repository collections is not permitted, except that material may be duplicated by you for your research use or educational purposes in electronic or print form. You must obtain permission for any other use. Electronic or print copies may not be offered, whether for sale or otherwise to anyone who is not an authorised user. 


\title{
11 The Flying Ants and the Beauty of Ice
}

\author{
Heidi Pietarinen and Eija Timonen
}

\section{Flying Ants and the Beauty of 'Ice'}

In Lena Tsueb's embroidered work Flying Ants (2016), the ants emerge from their nest after it rains. The ants are embroidered using colourful cotton yarn and translucent glass beads against black fabric. Tsueb, a member of the Ju/'hoansi San community from northern Namibia, relates how people collect and eat ants after it has rained. The embroidered language is culturally, visually and materially distinctive. Tsueb's beaded artwork Porcupine graced also the cover of an art book, Namibia, Land of Memories and More (2014), which presented 140 Namibian artworks exhibited at Venice Biennale 2015. At the same time, in the northern part of Finland, the artist Eija Timonen explored cracks, shapes and rhythms in frozen water through photography. For her part, her colleague Heidi Pietarinen was inspired by the tactile and colourful qualities of Timonen's photographs and wove her impressions into jacquard woven textile. Both artists were wondering how to connect the North and South through collaborative art-making practices, across cultural and geographical boundaries-proceeding from two- dimensional photographs to tactile and threedimensional textiles. Inspiration was coming forth from Tsueb's Flying Ants and Porcupine artworks.

At the beginning, 'Ice' described Timonen and Pietarinen's artistic cooperation based on the theme of ice, but later on, it developed to mean cross-cultural cooperation amongst Timonen, Pietarinen, eight Ju/'hoansi San beaders and the Omba Arts Trust. The joint 'Ice Project', a border crossing, started a non-verbal conversation. The emerging narrative (the conversation) was not only thought of solely as written history; rather, the emphasis was on the creative process and the works of art developed during the process. The artefacts played a vital part in building an understanding of processes and local resources, such as craft skills and locally available materials. The beaders embroidered at their own pace in their own homes and produced unique pieces of bead art. The inspiration the artists drew from one another and their different environments or elements was coming forth from the beaders' artworks. Otherwise, the patterns, topics and materials were free for them to choose. The outcome was a series of embroidered works encompassing an interesting combination of cultural and historical layers. These included images of northern ice, Namibian rock art and ostrich eggshell beads. 
This study focused on how different artists worked in response to the same theme and what kind of artefacts, material choices, themes, colours and other design elements came into play during the process. Our reflections on the study findings also revealed how multidimensional narratives and multiple cultural influences are conveyed by hand-woven and embroidered textiles and how powerful non-verbal communication comes about. The art-led method created in the project made it possible to observe the dialectic between cultures and identities. The target beneficiaries were San and Finnish women, for whom the project sought to provide opportunities to increase their creative engagement and highlight what they considered distinctive about their cultures while drawing inspiration from the ice-themed photographs. The aims of this study and the project were the same-to develop a method for multicultural artistic cooperation.

The creation of a border-crossing working culture between artists in northern Finland and a Ju/'hoansi San beader community in eastern Namibia was based on principles such as visibility of the authorship, mutual respect for knowledge and working methods, and challenging typical stereotypical conceptions by reimagining, e.g. the categories of the South and North. While we were not very familiar with the theme of decolonising at that point, later we learned that these are essential aspects when designing research practices from a decolonising perspective (e.g. Ridanpää, 2019; Sheehan, 2011; Tunstall, 2013, 2019). In order to give the works of art visibility and ensure that the names of the artists were acknowledged, the works were exhibited in Finland during the period 2016-2018.

Timonen has worked with Arctic art for over ten years. She has held a number of exhibitions and authored numerous research articles in this area. She has photographed both abstract structures and ice forms, mostly in the lake district of Eastern Finland, and has done still-life installations based on ice. The varying forms, structures and phases of ice play a major role in her photographs and paper collages, which are either colourful or black and white tapestries and resemble white, 'lacy' winter landscapes (see www.lightofice.net).

Pietarinen was inspired by the tactile qualities of Timonen's photographs. The colours under the frozen surface are natural, dark, rich and intense. Pietarinen wanted to incorporate both tacit knowledge (such as textures, weights and materiality) and three-dimensional woven structures into her design thinking, even though she was working from two-dimensional photographs. The photographs were like doorways to the narrative character of ice. She was also curious about the historical creative potential of the jacquard technique. With this technique, the yarns can be woven into an unlimited range of designs and multicoloured effects, bringing a great sophistication to the weaving process.

The 'Ice Project' may be understood as offering us a viewpoint to the aesthetic of postcoloniality. By this, we mean that we understood the process of multicultural artistic cooperation as equal and respectful design work that valued different starting points and aesthetics. To understand the aesthetic of postcoloniality, we needed to learn how to listen to the narratives and ideas of postcolonialism that originate from the South, but that can be connected to/with the North, for example, through collaborative art-making practices. The aesthetic of postcoloniality, in addition, is a specific referral to the postcolonial realities and context that most Namibians live in (Smith et al., 2020). People in the northern parts of the Nordic countries experience ice as a physical, multisensory and aesthetic facet of everyday life. As the aesthetic 
understanding of an environment has both individual and culturally shared meanings, there can be many interpretations of ice. One aim of this chapter is to explore how to continue the idea of multicultural artistic works and to inspire one another. A second focus is to analyse how different artists and practitioners were able to develop a design method and techniques at the intersection of different cultures. We have striven to pay particular attention to material differences that the 'Ice Project' provided. The photos, textiles and embroidered bead works were used as the material of artistic practice, rather than as functional design. We situated our material practices in the galleries and promoted reflection on ideas about identity and culture that hold our visual records of the past, present and future (Hemmings, 2013, pp. 24-26, 42; Sheehan, 2011, pp. 68-80). We were interested in what kind of perceptions ice would evoke in a context where instead sandy deserts characterise the natural environment.

Our research showed that the perception of ice was shaped according to the local culture. The art processes transcended language and cultural boundaries, referring to the ideas of artists drawing inspiration from one another's works, enabling more space and flexibility for making and expression that was informed by the experiences of the beaders. The results presented in this chapter are based on a series of open discussions on artistic themes between Timonen and Pietarinen about ice in the context of art and design during the years 2016-2017. A summary of the conversations revealed four themes: cultural understanding, spatiality, multisensory and colour. During the same years, the 'Participatory Development with the Youth' project (PARTY, 1 February 2015-31 December 2018) at the University of Lapland gave Timonen and Pietarinen an opportunity to collaborate with the Omba Arts Trust in Namibia. The project focused on developmental cooperation through research and innovation, staff exchanges, as well as sharing of knowledge amongst researchers, San beaders, other local actors in Southern Africa and international aid organisations (PARTY, 2017).

The PARTY project and the Omba Arts Trust, a registered Fair Trade organisation (FTO), helped the photographer, a textile artist and Jul'hoansi San bead embroiderers share their interpretations. Pietarinen spent a two-month period in Namibia during the years 2016-2017, when she visited the Omba Arts Trust and had discussions with its director, Karin le Roux. The purpose of the interview data collected from Le Roux was to, through the Trust, understand the cultural and environmental contexts. The artefacts were used as the data and visual analysis to interpret the work of the beaders. The data was embedded in the artworks. The key elements in this research were the following: the Trust is a growing company, has a Fair Trade mark, is a not-for-profit organisation, fosters a sustainable development model, improves women's life conditions and promotes textile design. The Trust supports the sustainable livelihood of marginalised communities through development, sales and marketing of unique Namibian handmade arts and crafts. For the past 20 years, it has collaborated closely with remote ethnic groups such as the Ju/'hoansi San community (Karin le Roux, personal communication, 9 November 2017; Omba Arts Trust, 2020).

Our approach was multimethodological, comprising multimodal image analysis (Räsänen, 2015, pp. 234-237, 367), thematic discussions (Bauer \& Gaskell, 2000) and concrete art-making. The research framework consisted of interpreting the processes in terms of cultural-based design (Walker et al., 2018). The aim of the research was to develop a method for multicultural artistic cooperation. Participants engaged in collaborative and art-led research that reflected a spiral of adaptable steps (see Table 11.1). 
In what follows, we first present the background of the art-making processes and the theoretical choices. Second, we examine the outcomes of the thematic conversations. Third, we discuss the artefacts created in light of the themes and designs. Fourth, we then go on to consider the economic and cultural context in which the artefacts were produced. Finally, we present conclusions, findings and insights gained.

\section{Pearls of the Kalahari}

Ju/'hoansi San beaders' artworks often include hand-carved ostrich eggshell beads, also referred to as 'pearls of the Kalahari' (Sarantou, 2014, p. 142). The beaders have no formal training, but rather convey insights into their unique culture and everyday life. The composition and range of colours in their bead art affords a unique view into their day-to-day life.

There are over 34,000 San living in Namibia, and they remain one of the most marginalised communities in the country. The San are Indigenous inhabitants of Southern Africa, and today the majority of the San live in Namibia, Botswana, South Africa and Angola. They belong to a group of hunter-gatherer peoples called the San or Khwe, meaning 'first people' in most cases. Their ancestors roamed the southern part of the continent for thousands of years, leaving a legacy of rock art, and their history has been widely documented and studied (see Hemmings, 2015, p. 210; le Roux, 2004, p. 2, 2014b, p. 276; Sarantou, 2014, p. 138).

Karin le Roux has worked in the craft sector since 1991. With support from the Omba Arts Trust, community members fashion intricate handmade and Namibiandesigned artefacts, such as jewellery, woven baskets, and Art-i-San printed fabrics (the name of Omba Arts Trust's textile and jewellery collection, as well as accessories and contemporary Namibian Bushman art in various media including lino prints, beaded art and paintings). These artefacts hark back to distant ages in Indigenous history, one example being the use of beads made of ostrich eggshells, which archaeological studies indicate is a 40,000-year-old tradition. These age-old craft-based traditions have typically produced works for the community's own use (le Roux, 1993, 2014a, pp. 86-89, 2014b, pp. 276-277; Karin le Roux, personal communication, 9 November 2017).

This specific group that we worked with, Ju/'hoansi San women, live in Drimiopsis, in the Omaheke desert, but their artworks are marketed and sold in two stores located in the Old Breweries Craft Market (Garten Street) in Windhoek. When visiting the Craft Market, one cannot avoid thinking that 'This is cultural superficiality', because a wide variety of Namibian artefacts from different cultural groups are for sale in one place. This suggested that people have certain strong preconceptions about Africa, just like they do about northern exotics. Although Indigenous craft-making, such as bead work, in Namibia is rooted in Ju/'hoansi San beaders' methods of production, many artisans have surrendered to the demands of tourists to depict ideas about the region not necessarily associated with an Indigenous San beaders' style. Thus, the question would be: What would the signifiers of the beaders' art look like? In our case, bead art is a tradition that multiple cultures lay claim to originating, so it provides an articulate critique of the notion that any identity, human or material, can be narrowed down to a single source (Caley, 2019; Hemming, 2013, p. 33). However, Namibian art and craft markets can be seen in a wider perspective if one visits the village of Penduka in Katutura Township in Windhoek, Karakulia weavers in Swakopmund and the Visual Arts Department at the University of Namibia. Embroidery in Penduka (meaning 
'wake up') is practised by Namibian women's groups in various styles and uses a variety of techniques. Karakulia weavers produce high-quality carpets from karakul wool, and university students display their printed fabrics proudly in university galleries (Hemmings, 2015, p. 218; le Roux to Heidi Pietarinen, personal communication, 11 November 2016; Sarantou, 2014, pp. 24, 99, 102-103).

Perhaps, due to the limited market that exists in Namibia, the main market for the Omba Arts Trust's products is the US. Most of the materials are sourced from the 'natural' Namibian environment, so the vulnerability of Namibia's environment, the country's poverty and the lack of materials often figured in discussions with le Roux. Pietarinen decided that materials with cultural and locational significance, such as hay and ostrich eggs, would not be used in this project; this was one way in which sustainability was considered. The Omba Arts Trust's remit was to provide materials and equipment, such as printed photographs, glass beads, threads, fabrics and needles, through which the San could express themselves in their art. The beaders' materials choices for their work were purchased by the project, so they used contemporary art materials and techniques. One might ask why Ju/'hoansi San beaders were interested in co-operating with us when they could have made products for tourists. We had promised unconditionally to buy all the beaded works made as part of the project, regardless of the outcome. However, as our project emphasised experimental design, it set no systematic production targets. This arrangement and the promise that we would buy the final artefacts provided the San artists an opportunity to experiment with colours and styles, such as thematic combinations between rock art and Arctic motifs. These limited resources contributed to the creation of unique artefacts in small quantities.

Sustainability can be seen in the beaders' choices of materials, which had been recycled, as well as in production, which was linked to everyday life and thus offered an opportunity to socialise, share personal issues and receive emotional support from other members of the community (le Roux, personal communication, 5 October 2017). The process drew on local resources such as craft skills and locally available materials. These reflected from their everyday life, were collectively articulated and given a specific surface design for beaded artworks. (Fletcher, 2008, p. 141; Omba Arts Trust, 2020; Sarantou, 2014, pp. 134-135, 138; Smith et al., 2020, p. 97)

\section{Art-Led Research}

The art-led research method (Smith \& Dean, 2009; Vaughan, 2017) adopted in the project offered possibilities to explore the relationship between materials and the crafters' artistic expression. Accordingly, the focus of the 'Ice Project' was the interplay between the researcher-practitioners and the design or crafting processes. The emphasis was on the creative process and the works (photographs, textiles, beaded artworks) that emerged from that process: the artefacts played a vital part in the new understandings we gained of practice and designers' design processes (Akimenko, 2018, pp. 9-10, 32-33, 194-198; Nimkulrat, 2009, pp. 27-32, 36-37; Timonen, 2019; Tunstall, 2019, pp. 240-245).

Le Roux invited the eight beaders from the same village in eastern Namibia, a group consisting of Mara Britz, Anna Doeses, Katrina Kous, Martha Kavandjinje, Cristofina Noues, Josefina Stuurman, Magdalena Stuurman and Lena Tsueb. Despite differences in age within the group, each member was responsible for her family, making the work a serious undertaking financially as well as artistically. 
The beaders used glass beads to create embroidered works reflecting their interpretations of Timonen's photographs (Figure 11.1) and Pietarinen's jacquard textiles, an example of an interpretation of Timonen's (2018) photography of ice (Figure 11.2). The first series of eight embroidered artworks $(25 \mathrm{~cm} \times 35 \mathrm{~cm})$ were finished as of March 2017, and the second series as of June 2018 (Figure 11.3). The eight beaders each made one work at a time.

The making processes resembled a multimodal image analysis, which involved the recycling of visual culture products—other images and artefacts—as the starting point for one's own design and production. The interpreting of existing illustrated pictures is motivated by the underlying perception of post-modern art theories that images are generated from images (Räsänen, 2015, pp. 234-237, 367). The jacquard textiles and beaded artworks embodied personal interpretations of photographs by the textile designers and beaders. This did not mean they sought to imitate the photographer, but rather, that they endeavoured to convey the meanings through new images that came to mind during the art-making process. Neither Pietarinen or the San beaders copied the images directly, but instead edited, replaced or omitted parts of them in the design process. This kind of conceptual process transformed Timonen's photographs into other images; that is, jacquard textiles and beaded works. This required an ability to find analogies and present things in a new way.

The multimethodological approach allowed Pietarinen and Timonen to play an active role in collecting visually and tactually interesting surfaces and to embrace culturally significant designs, narratives-that is, beaded artworks. The artworks themselves were the data. The aim was to investigate design and crafting processes that would enable us to help the beaders become actively engaged in the project by providing them with a platform (bead work) and inspiration (photographs). The mixing of qualitative data collection techniques, such as interviews, and content analysis of culturally significant Namibian craft, textiles and photographs was vital to gaining an understanding of the shared theme. The experience of putting together the exhibitions 'Kalahari Highway' in Rovaniemi (2018) and 'Icy Metamorphoses' in Joensuu (2018) showed that different artworks could be presented side by side, and that all the stakeholders were presented in the same space at Gallery Valo in Rovaniemi (2018).

The participants engaged in collaborative and art-led research that reflected a spiral of adaptable steps: 1) thematic conversations between Pietarinen and Timonen exploring a shared theme (ice) that was inspired by the Namibian artist Lena Tsueb's work; 2) developing an action plan (trips to Namibia in 2016 and 2017); 3) reflecting on and investigating the ice (photographs, textiles and beaded artworks); and 4) implementing the plan (exhibitions). The same kind of structure can be seen in Cassidy's Participatory Action Research (PAR) (Cassidy, 2018, pp. 277, 285). PAR assisted Pietarinen and Timonen in developing strategies for collaborating with the San beaders in order to reconstruct the meanings and values of the traditional knowledge and skills that the group shared and to provide avenues to explore and understand the cultural significance, meanings and values that were shared in the project. The exhibitions were documented by photographing them and keeping working diaries, which focused on materials, colours, structures and other elements of design.

Table 11.1 shows how the present art-led research unfolded as a visual and tactile investigation into the photographs created as part of the project.

Neither ethnographic approaches nor participatory research (MacIntyre, 2008) proved applicable in the present project due to the lack of contact. Pietarinen did 

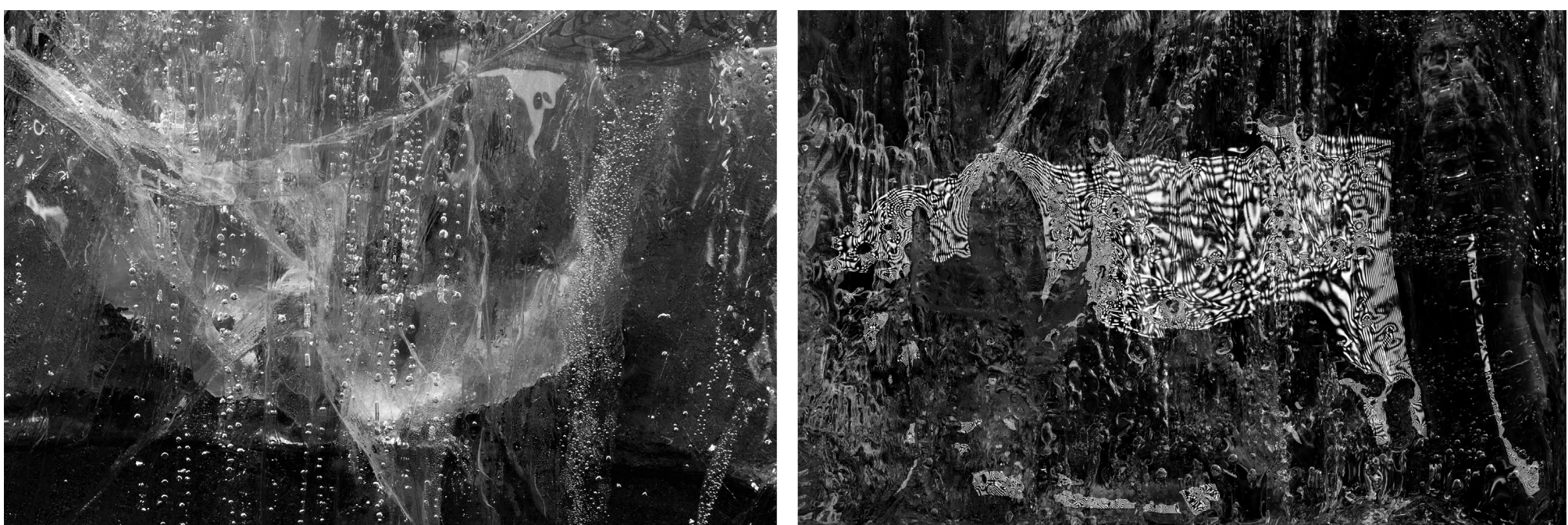

Figure 11.1 Eija Timonen, If Kiss ... (2014), colour pigment print, diasec, glossy, $90 \mathrm{~cm} \times 60 \mathrm{~cm}$ and A Safari (2016), colour pigment print, diasec, glossy, $80 \mathrm{~cm} \times 54 \mathrm{~cm}$. 

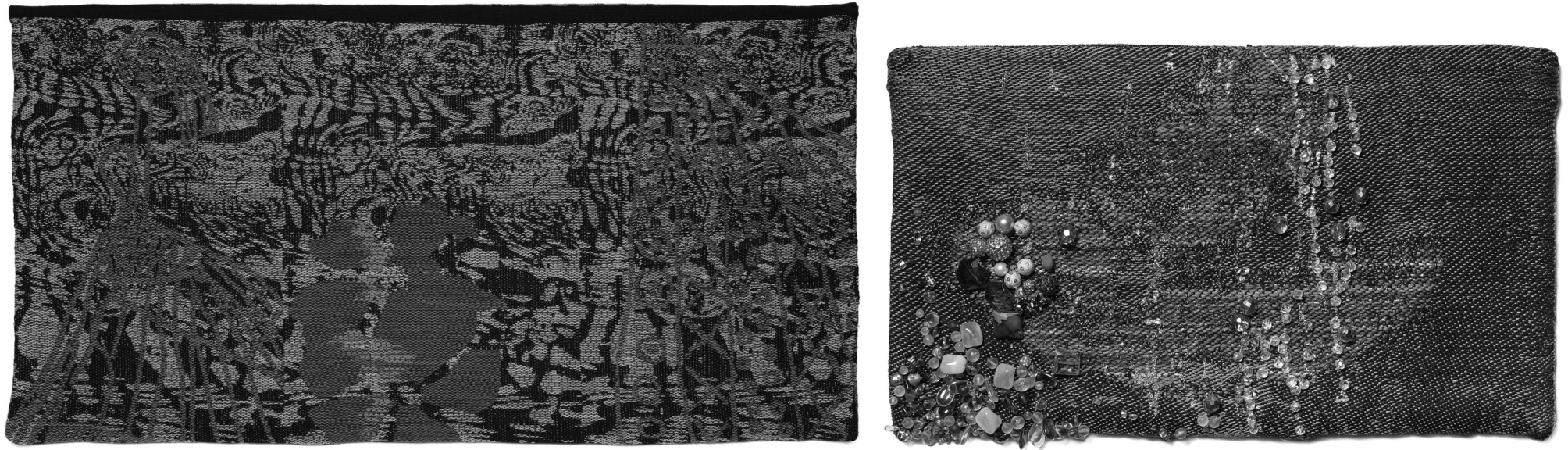

Figure 11.2 Heidi Pietarinen, Red Lips (2016), jacquard woven textile, $50 \mathrm{~cm} \times 30 \mathrm{~cm}$, based on Eija Timonen's If Kiss ... photo, and Africa (2016), jacquard woven textile, $50 \mathrm{~cm} \times 100 \mathrm{~cm}$, based on Eija Timonen's photograph A Safari. 

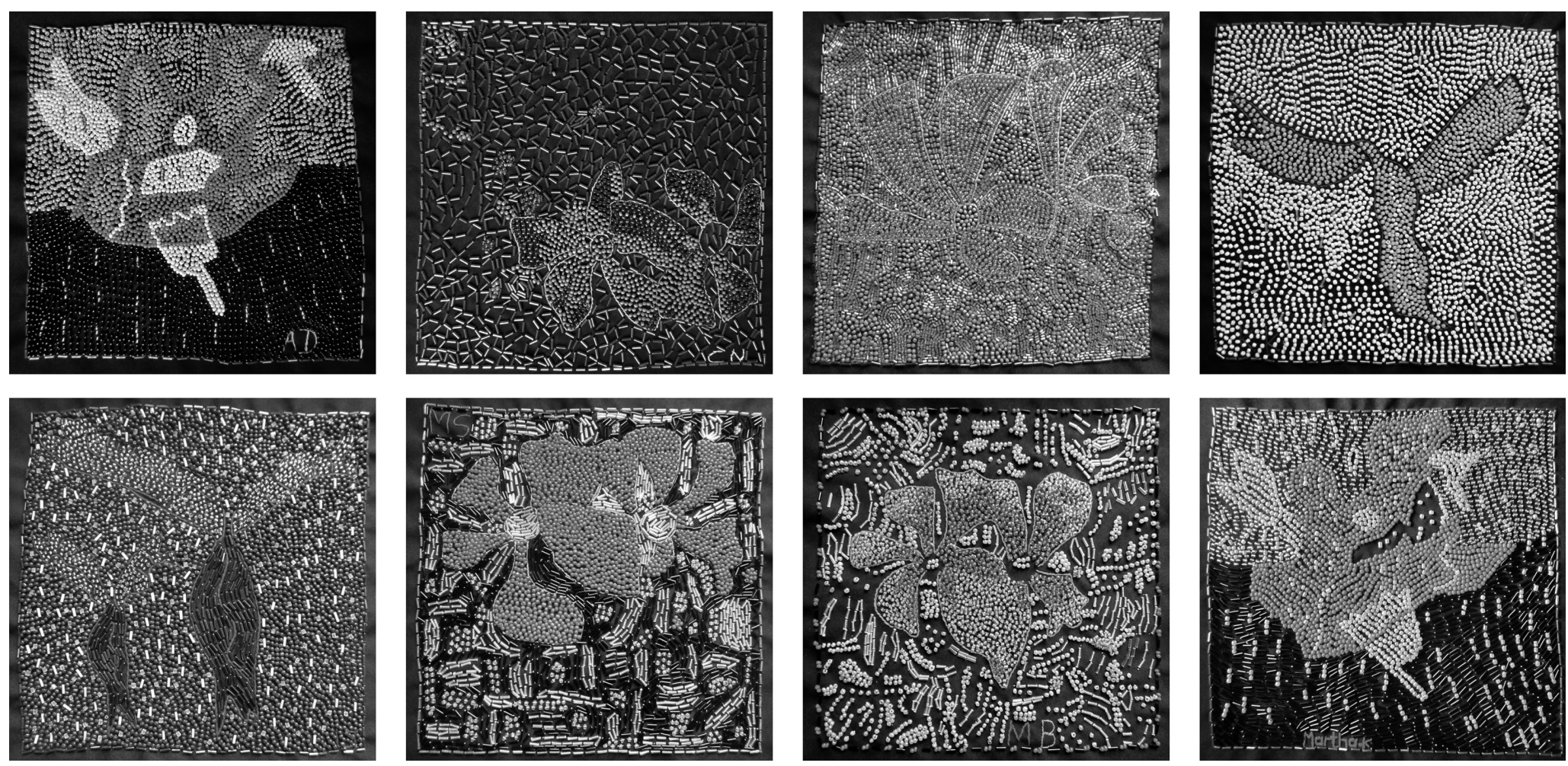

Figure 11.3 Martha Kavandjinje, Mara Britz, Anna Doeses, Katrina Kous, Magdalena Stuurman, Cristofina Noues, Josefina Stuurman and Lena Tsueb’s Beaded Art Works (2017) and beaded panel, $35 \mathrm{~cm} \times 45 \mathrm{~cm}$.

Source: Omba Arts Trust 
Table 11.1 The present art-led research as a visual and tactile investigation into photographs, woven textiles and beaded artworks on the theme of ice

\begin{tabular}{cccc}
\hline $\begin{array}{c}\text { Eija Timonen } \\
\text { Ice } \\
\text { photos }\end{array}$ & Reading & $\begin{array}{c}\text { Cultural } \\
\text { understanding }\end{array}$ & Artworks \\
\hline $\begin{array}{c}\text { Heidi Pietarinen } \\
\text { jacquard } \\
\text { woven } \\
\text { textiles }\end{array}$ & $\begin{array}{c}\text { Implementing and } \\
\text { refining the plan }\end{array}$ & Colours & \\
$\begin{array}{c}\text { Omba Art Trust } \\
\text { Jul'hoansi San } \\
\text { beaders }\end{array}$ & $\begin{array}{c}\text { Reflecting on and } \\
\text { investigating the issue }\end{array}$ & Spatiality & Exhibition \\
& $\begin{array}{c}\text { Developing } \\
\text { an action plan }\end{array}$ & Multisensority & \\
\hline 1. DEFINITIONS & 2. DISCUSSIONS & 3. ARTWORKS & 4. PRESENTATIONS \\
\hline
\end{tabular}

not interview the participants-the San beaders. The artworks themselves were the data and visual analysis that refers to signifying were used to describe the beading art. This decision was made for practical reasons: Timonen did not visit Namibia, but Pietarinen spent short periods of time in Namibia (two one-month visits), and le Roux's trips to meet the beaders did not coincide with these. The San people live and work in isolated conditions, and access to Drimiopsis, in the Omaheke desert, is possible only by four-wheel-drive vehicles after a lengthy drive on a gravel road (Malan, 1998, p. 108; Sarantou, 2014, pp. 30, 137). So, textiles and photos were the most portable materials and could be moved relatively easily, compared with the other artefacts, such as ceramics and jewellery. San beaders believe that they have always communicated with each other inside and outside of their community through artefacts. This dimension of communication is called 'fabric tell[ing] a story' (see Shineshine, 2017). This addressed the 'situatedness of the author' and therefore sought to address power relations within design practice. This created a space of mutual understanding whereby the photographer, textile designer and San beaders were fully engaged and were able to share their own experiences in the design process (Smith et al., 2020, p. 98). Accordingly, in this case, communication through textiles could be described as invoking a tradition and using fabric to tell a story. Textiles have received little attention in post- and decolonial studies, despite the ability of textiles to capture and convey cultural, national and individual identity. Within the hierarchies of power that rule the visual arts or the market value of art, textiles are often regarded as a marginal art form (Hemmings, 2013, pp. 24-25).

\section{Cultural Understanding-Ice, Culture and Rock Art}

Culturally shared aesthetical and metaphorical experiences of ice are part of everyday life in Finland. Our personal experiences of walking, playing, skating or skiing on ice 
have a great impact on how we observe and interpret ice. Ice is a richly expressive element in the Finnish language, poetry, literature and design. Ice has been an inspiration for many Finnish designers, one being textile designer Elsa Montell-Saanio. Both Finnish designers and beaders' creativity sprang from a desire to observe nature and to see sky.

For obvious reasons, ice was difficult to interpret for the San beaders. In Namibia, one cannot visualise real ice; the only image that exists in this context is that of an ice cube. The weather is generally fair and sunny, with an average of 300 days of sunshine annually. The beaders' works drew on materials and textures: different materials (fabric, yarns, beads), structures and colour combinations dominated the surfaces. Another dominant feature of the surfaces was geometrical shapes, which were simple and elemental against the black background. The variations of the bead directions shaped motifs from fine to rougher textures. The tactility and three-dimensionality of the bead artworks were highlighted by using shiny, matte and translucent beads in the same work. The visual and tactile image of a densely or sparsely embroidered surface served to evoke a fragile ice or snow crust, while flower-like images in the ice were transformed into the wild plants that the beaders actually gather. The beaders found it challenging to interpret the transparent, white ice flowers in the photographs; ultimately, these became bright red, pale yellow and night-blue flowers. Initially, the beaders also found the random cracks of ice challenging to translate into bead artwork. When embroidered, the angular shapes of the ice in the photographs were rendered as geometric forms, such as triangles (Figure 11.3).

Mara Britz, Magdalena Goieman and Josefine Stuurman were especially inspired to explore the rock art and engravings of their ancestors-the oldest dated at 27,000 years-that are found all over Namibia. Rock art is a proof of the cultural heritage of the San and tells the story of the Bushmen's hunting, mythology and shamanistic rituals. Even though these three beaders had not literally seen the rock art, they still used it in their art to express themselves. The bead artworks included animals such as elephants, giraffes and zebras, which were dancing freely on the surface of the panel, similar to paintings on rock. The patterns they embroidered were visual representations of their daily life-animals, plants and everyday life in their home village (Coulson \& Campbell, 2001; Forssman \& Gutteridge, 2012; NASCO, 2019). Later on, the beaders began to develop their own imagery, and the results were presented in a landmark exhibition of contemporary Namibia San Art called 'Roots of the First Tree' in the National Art Gallery of Namibia in 2019. This part of the project clearly demonstrated the elements that the San beaders considered to be distinctive about their culture: the stories passed down from their elders or their daily existence.

Through such cultural processes, the images of northern ice and southern rock art were intertwined: our project unified the designers and makers with the environment and the body of the work. The beaded art that was produced could be understood as a story from the beaders' community in which they sought to share significant elements of their reality (Sarantou, 2014, pp. 136, 138; Wood Conroy, 1997, p. 2).

The flower patterns in the ice prompted a number of other complex questions that are not easy to answer. Was the project, which originated from a foreign society, alienating San beaders from their own way of making beaded art, or was it reinforcing creative processes that relate to their communal life? Did the project maintain or violate their cultural authenticity? After all, they had to survive by making a living from their bead art. 


\section{Spatiality}

Spatiality took many different forms both in the discussions between Pietarinen and Timonen, and in Pietarinen's field notes (material-based travel diaries) in Namibia. Walking on a frozen lake surface during the wintertime or in the sand in the Kalahari desert enables one to visualise very clearly how the three-dimensional natural scenery of a northern winter landscape or a African sandy desert can be seen or felt. A wide, icy lake and a huge desert area open up freely to the horizon and frame the sight without any impediment in the landscape. The feeling of the spatiality is strong. The ice and sand become intimately mixed with the multisensual experiences. Pietarinen also collected and saved the sand to be able to later choose the right coloured yarns for weaving. In our conversations and material-based travel diaries, these two- and threedimensional experiences were mixed together. What is more, as a material, the ice in a frozen lake and sand in a desert are experienced three-dimensionally: they have depth, width and length. But, when saved as image files, seen on a computer screen or printed on paper, photos of ice or sand are two-dimensional, even though they refer to a threedimensional world. The ice and sand are like multilayered woven textiles: ice and sand reveal something about their different layers, about having diverse options and about the past. This can be seen, for example, in Pietarinen's (2018) Sirocco jacquard.

If one looks at the surface of woven artefacts in a photograph, it is two-dimensional, whereas a jacquard textile evokes three-dimensionality with its uneven surface. This two- and three-dimensional association raised the question of how to translate Timonen's photographs If Kiss . . . (2014) and Safari (2016) into jacquard textiles. Pietarinen started by developing colour, construction and texture palettes to compose images and a TC-1 loom for weaving. The rough surface created shadows and accents, elements of drama in what was seemingly a flat woven surface. The threedimensional spatiality of colours was impressive. However, colours cannot only be seen as a two-dimensional surface in a rug, but also enhanced by the warm red colour in different shades. The final weavings were based on the original photographs and material samples (e.g. sand, swatches, shells), because Pietarinen used these as a source to weave from, taking note of colour, balance and proportions and going on to recreate these in a woven fabric. Pietarinen may have worked with colours, layers, filters and all sorts of enhancements along the way to do the photographs and material samples justice, but the last step was the flattening and conversion of the design file into a single two-dimensional layer of black and white pixels (see Schlein \& Ziek, 2006, pp. 25, 47; Selby, 2011, pp. 11-23). Woven structures were drawn together from different two- and three-dimensional sources (such as wintry environments, photographs and woven textiles) with the photographs If Kiss . . . and Safari used as starting points.

Just like the textile artist Pietarinen, San beaders also found it challenging to interpret and convert images into bead art, as they also had to ponder questions of twoand three-dimensionality. The San visual language is culturally unique. They have worked with beads-either ostrich eggshells or glass beads-for centuries, and today, bead art is still given as gifts to promote friendship and social harmony (le Roux, 2014 b, p. 276). San women have a visual language of their own. They are keen on decoration, such as coloured and textured beads, but the purpose is not decoration as an end in itself. The patterns also form an integral part of bodies, functional items and the social fabric of the Ju/'hoansi San culture. The pattern conveys a strong local 
identity, which references animals, plants or objects as a way to explain daily life (le Roux, 1993, pp. 20-21). The final beaded artworks were flat but had a graphic quality to them-just like that seen in Art-i-San screen-printed textiles-which made the images instantly recognisable (see Hemmings, 2015, pp. 213, 217-221).

As the shape of the photographs and textiles was naturally not uniformly square, an embroidered image could represent part of the source image. A sufficiently large piece of fabric $(35 \mathrm{~cm} \times 35 \mathrm{~cm})$ and a substantial number of beads turned out to be better for interpreting the image, because it was difficult to embroider details in a smaller panel. The basic idea was to give simple objects (photographs and textiles) and artefacts (beads) to self-educated designers and work with them to visualise new designs; that is, interpretations of ice. The input that came from self-educated designers became a form of 'designing with', as the beaders' work was based on their knowledge, understanding of local culture and environment and was a fully creative endeavour on their part-as designers (Kolko, 2012, pp. 42-47). This part of the process was also an example of shifting from one space to another. Walking on a wide frozen lake or desert creates an experience of wideness, while embroidering or weaving a textile often gives an experience of smallness.

While San beaders were unfamiliar with typical Western textile design conventions, such as the tone-to-tone colour system, the system of repeating patterns or the logic of striped and checked patterns, they obviously knew very well their own local traditional conventions, learned in their own society. There is a long history of the production of traditional textiles in Namibia-for example, basket weaving (Cunningham \& Terry, 2006) - but often the textiles referred to as 'traditional' in Namibia include 'trade cloth' introduced by European traders and missionaries as they were adopted into use in traditional costumes, such as ondelela (a striped cotton fabric), which is used in Ovambo traditional clothing (Caley, 2019; Sarantou, 2014). Yet, Indigenous people prioritised Indigenous aesthetics, such as pattern and colour choices when selecting textiles from traders (Caley, 2019; McBrinn, 2017, p. 112).

Textures and surfaces are not merely seen optically; instead, the interaction between cultures is intertwined in the visual process. The real value of this 'designing with' process is not only the final results (beaded artworks), but also its value in underpinning this interaction and the most important aspects of cultural dialogue. The cultural dialogue involved various artistic expressions, from embroidery art to jacquard weaves and photography, and continuous-yet evolving - cultural and environmental interpretations by all the artists. Designing in multicultural context provided the opportunity to enrich design with new perspectives, which was one of the bridging powers throughout the project (see Smith et al., 2020, p. 97). For example, Pietarinen found how the emptiness of space or fullness of colours would change when women of various ethnic groups inhabiting parts of Southern Africa, such as the Ovambo, San or Herero were walking on the street or entering a room (Shoup, 2011, pp. 235236). The Ovambo dresses are made from a distinct material with bright pink, red and black stripes. Herero women wear voluminous Victorian-style dresses, complemented by horn-shaped headgear which fill the whole entrance to a room. The San people's dresses are much lighter-tanned springbok skins peppered with elaborately embroidered beads. San and Herero women look very different. A female garment, a dress with a voluminous, oversized silhouette, decorated or dyed, is used to emphasise the physical presence of the wearer, but can also be used as a tool for visible self-assertation. 


\section{The Colours and Flavours of North and South}

Can the slow movement from a fuchsia to a tangy red express the aroma of the red lingonberry or the bitterness of its taste? As we know, synesthetic experiences of the senses convey stimuli to all the senses involved. Sound may appear as colours or flavours (Haverkamp, 2013). As a textile artist, Pietarinen was thinking of synesthetic experiences when searching for possibilities to interpret the colours and translucency of Timonen's photograph If Kiss . . . . Ultimately, she decided to follow the colour scales in the photographs, but the challenge was how to translate millions of colours into the limited number of colours available in the yarns.

The experience of ice in the photograph If Kiss . . . differs from the experience of ice in the wild. Ice offers multisensory and deeply aesthetical experiences and has multisensory features, such as smell, sound, feel and taste. For example, in the hands of a textile artist, the red shades of If Kiss . . . are like the different shades of red Tencel yarn, which is a soft, silky, shiny material which does not wrinkle easily and feels soft against the skin. Materiality can be described in terms of a concrete material or the countless tools that guided the photographing, weaving or embroidering in the 'Ice Project', examples being cameras, shovels, brushes, loom, yarns, a whiteboard and image processing programmes (see Barrett \& Bolt, 2013; Bolt, 2009; Siukonen, 2011).

Materiality is also associated with material thinking. Knowledge of materials guides the design and work of professionals. This work is guided by working processes and conditions. Material is associated with knowledge of the substance, identifying connotations and cultural meanings and being familiar with the relevant methods and tools. Thus, materiality is multifaceted and multilayered, with tangible materiality and abstract materiality being intertwined (Barrett \& Bolt, 2013; Mäkiranta \& Timonen, 2015).

Natural ice is associated with the colour white because an icy lake is mostly covered with snow. White brightens other colours in photographs, but in a woven fabric, a white warp may extinguish the colours in the weft, which then become more or less opaque pastel colours (see Rihlama, 1997, pp. 110). Natural ice changes reflections. In the sunlight, the surface of ice brings out the entire colour spectrum and reveals the world under the icy surface, with its colourful stones and plants. Pietarinen studied the main colours of Timonen's photographs and reduced them to a woven format. Both literal and metaphorical conversations on colours between Pietarinen and Timonen revealed that translucency, the colour spectrum and reflections were the most important features for understanding the colours of ice.

The Namibian context offered a particular opportunity to see colours. The colours in Namibia evoked an affinity in Pietarinen's mind of the natural world. The wooden or organic art and craft objects (palm leaf baskets, wood carvings, etc.) are coloured by an earthy palette of natural materials, with tans, browns, ochre, ebony and ivory. Windhoek, the capital of Namibia, and its surroundings, such as Katutura, the old apartheid township, revealed the colours of burnt orange, a mixture of blue and green, hot apricot and the brown of dry sand. These brighter colours are seen in the Omba Arts Trust's palm leaf baskets, bead art and printed textiles, which are dyed, embroidered or printed with bright blue, green, red and orange colours. Words hardly capture the feel of the colours of Namibia or ice because the visual, tactic, kinetic and emotional experiences are difficult to translate into words. Indeed, the understanding of colours is linked to the environment and to the surrounding culture. These 
also guided interpretations of ice-from the northern transparent ice flowers to the southern blossoms.

\section{Conclusions-Future From Tradition}

This study focused on how different artists worked with a shared theme. The inspiration the artists drew from one another and their different environments or elements, such as material choices, colours and other design elements, were used in the art process. We used multimodal image analysis, thematic discussions and concrete artmaking to find out how different artists work together employing a shared theme. Their attitudes and ways of defining or making differed because they came from different cultural contexts. In fact, the project could have failed at an early stage because of the many potential uncertainties stemming from different cultural considerations.

In the beginning, the beaders were confused because they had received the photographs and materials but there were no clear guidelines. Due to the very nature of the project, all the interpretations and technical implementations were left to them to freely choose and decide on. When they had negotiated this phase of the process, they were excited and strongly engaged in the project. An openness was a crucial part of the approach because we worked at the level of the individuals and wanted to build relationships of accountability with the beaders. Also, one of the most important values of the project was respectful design (Sheehan, 2011). The authors did not give instructions but trusted that the Ju/'hoansi San beaders would choose materials, colours and forms in accordance with their culture. We structured the project so that we could work with the beaders through a process in which they would navigate through a narrative tradition. We designed the conditions of storytelling without words, using fabric to tell a story. The photos, textiles and beaded works deserve a close reading, which should be understood as more than textual, because they merit scrutiny, just like any other materials, design methods and multisensory disciplines (touch, taste and smell) (see Hemmings, 2013, pp. 24-25; Tunstall, 2019). Perhaps, there is a moment when researchers should listen 'around and beyond words' (Daniels, 2011, p. 10; Jansen, 2019). We appreciated the Omba Art Trust's visual way of thinking instead of thinking with words. As San designer Bertha Christof stated in the exhibition 'Roots of the First Tree', organised in Namibia: 'We see culture in these pictures' (NASCO, 2019 , p. 24). The project operated as a cultural 'agent', challenging the stereotypical conceptions by reimagining, e.g. the South and North, the emptiness of space on ice or in a desert or the fullness of colours of specific cultures in a novel and atypical way. Similar observations have been made as well by cultural geographer Juha Ridanpää (2019, p. 132; see Sheehan, 2011).

The works of art shifted from traditional to innovative embroidery art. It was fascinating to see how our views were thoroughly shaken. We were so caught up in our own way of interpreting ice that encountering a different aesthetic refreshed, amazed and, at the same time, laid bare our own cultural conventions. What would many European cultures even be today without the historic influence of transnational textiles? Ridanpää's $(2019$, p. 137) postcolonial perspective requires eliminating the obstacles to being creative from one's own cultural point of view. This view is also supported by Tunstall's (2013, p. 240) views about 'mutual borrowing that happens among value systems and cultures'. Design innovation has been argued to extend colonial and imperialist traditions; for example, Tunstall (2013) highlights how design innovation 
practices uphold artificial divides between art, craft and design. By engaging in Tunstall's (2013, pp. 238, 244) guidelines for a decolonising approach, which she titles 'design anthropology', the project acknowledges its 'aesthetic objects' as 'repositories, transmitters and vehicles for the exploration and construction of knowledge'. The project refers, although only partially, to Tunstall's (2013) design anthropology, by additionally acknowledging that borrowing between the northern and southern cultures occurred, that unequal circumstances between the cultures existed, but that the project sought to engage in small steps to mitigate some of the inequalities (Tunstall, 2013, p. 241). The project acknowledged the cultural dynamics involved, as well as the benefits and drawbacks that eventuated through the new creations (p. 240).

Our primary goal was to meet the artists from diverse backgrounds and address a common theme with them from different perspectives. After we first had ourselves interpreted the work of the Namibian artist Lena Tsueb's Flying Ants in our artistic work, we became interested in what kind of expression the Arctic theme-ice-would create in the desert environment. Our research showed that artistic expressions of different environments were bound to the local culture. In the desert environment, ice appeared as a colourful element and as a part of its flora and fauna. Despite not having common language, the artists were able to work cooperatively across continents. Art-making transcended the linguistic and cultural boundaries. As a result of this project, the authors of the chapter learned about multicultural artistic collaboration and gained important experiences that can be utilised and developed further in future projects when working with artists from diverse contexts.

The San beaders' embroidery process allowed us to gain an insight into their world in ways that observations and interviews could not have allowed us to do. Especially this refers to the art-making process. It was linked to everyday life and offered an opportunity to socialise, share personal issues and receive emotional support from other members of the community. When people can use their own expressions and languages, it is empowering and may help in addressing social injustices. This is a dynamic way of making meanings in contextual environments (Daniels, 2011, p. 13). The starting point-what we have previously called a 'decolonising perspective'enabled cooperation on an equal footing, whereby all the artefacts made by the artists were equally valuable keys for intercultural dialogue.

The combination of beads, colours and embroidered accents gave each of the eight works an individual character. Each was made from beginning to end by one woman, who embroidered her initials, for example, 'LT', on the front of the panel. On the back of the panel, there is a short story about the women of the Ju/'hoansi San community and a label with 'Omba Art' and the name of the woman who made it, an example being Lena Tsueb. All the participants were free to choose the materials, colours and sizes of the beads they used.

The 'Ice Project' has a contribution to make to a wider multicultural discussion. Collaboration between Finnish designers and the Namibian Ju/'hoansi San community marks a step forward in crossing international borders, bridging language and cultural boundaries with colours, materials and visuals (photographs, woven and embroidered textiles). This is a particular kind of a commitment and demonstrates a deep understanding of what a shared theme is about. The project is an example of how Ju/'hoansi San women designed as members of a multicultural team and produced works representing something different to 'exotic' arts and crafts. Indeed, during these times of globally shared habits and meanings, respect for rich, locally-based 


\section{Heidi Pietarinen and Eija Timonen}

traditions, rituals and symbols is called for (Carlson \& Richards, 2011; Kuure et al., 2016, pp. 104-129). We could look even further and consider values, such as authenticity, originality and aesthetics.

The 'Ice Project' is also a good example of how the term 'cultural heritage' has considerably changed in respect to content in recent decades, partially owing to the instruments developed by the United Nations Educational, Scientific and Cultural Organisation (UNESCO). The cultural heritage includes traditions and living expressions, such as oral traditions, social practices, rituals, knowledge and practices relating to nature and the skill of producing traditional crafts (UNESCO, n.d.). The cooperation described here between Finnish and Namibian Ju/'hoansi San artists has shown how our interpretation of the surrounding nature is linked to our perceptions of the environment and culture.

The meeting of cultures described here can be captured metaphorically in a pearl. Textiles underlined and highlighted the three-dimensionality of the ice in the photographs: Pietarinen wove textures that were transparent and rough, whereas the beaders used colourful glass beads of equal size. The beaders' form of expression was different due to their varied experiences of ice. Together, however, they built polyphonic representations that were underpinned by their local knowledge. The works of art were results of communication-based readings of photos and textiles; a material reality about the photographer, textile designer and beaders' experiences and knowledge, not conceptual aspects of it. The artists produced multicultural and collaborative material representations based on the values of their respective creative visual cultures. It taught the authors how to explore cross- and interdisciplinary encounters between art, craft (skills and material practice), design and knowledge emerging from multicultural sharing experiences by using remote-but shared-connections. The authors also learned that narratives should not be thought of as mere written or spoken history, but as avenues for doing and in thinking. In the future, a new functionality of materials displayed digitally may increase access to unique cultural materials, and bring together artists across social and economic boundaries. Different cultures can teach us how to recognise and appreciate the forms and contrasts of materials, colours and textures. This may enable us to create shared futures through the sharing of traditional knowledge.

\section{References}

\section{Non-Print Sources}

Mäkiranta, M., \& Timonen, E. (2015, April 10). Material thinking as the basis for art-making processes, in the short film Possible Words and the video installation The Light of Ice. Asian Art and Humanities Conference, Osaka, Japan.

\section{Interviews}

le Roux, K. Interview. Conducted by Heidi Pietarinen, 11 November 2016.

le Roux, K. Interview. Conducted by Heidi Pietarinen, 5 October 2017.

le Roux, K. Interview. Conducted by Heidi Pietarinen, 9 November 2017. 


\section{Print Sources}

Akimenko, D. (2018). Narrative spaces: On identity work and placeness through arts-based narrative practices. University of Lapland, Faculty of Art and Design.

Barrett, E., \& Bolt, B. (Eds.). (2013). Carnal knowledge: Towards a 'new materialism' through the arts. I. B. Tauris \& Co.

Bauer, M., \& Gaskell, G. (Eds.). (2000). Qualitative researching with text, image and sound: A practical handbook. SAGE Publishing.

Bolt, B. (2009). The magic is in handling. In E. Barrett \& B. Bolt (Eds.), Practice as research approaches to creative arts enquiry (pp. 27-34). I. B. Tauris \& Co.

Bolt, B. (2013). Toward a 'new materialism' through the arts. In E. Barrett \& B. Bolt (Eds.), Carnal knowledge: Towards a 'new materialism' through the arts (pp. 1-14, 29-40). I. B. Tauris \& Co.

Caley, M. A. N. (2019, November 19). A reflection: The intersection of trade cloth and Indigenous crafts among the Vakavango. Intertwined Histories, 150 years of FinnishNamibian Relations. https://sites.utu.fi/intertwined-histories/a-reflection-the-intersection-oftrade-cloth-and-indigenous-crafts-among-the-vakavango/

Carlson, D., \& Richards, B. (2011). Design + culture: A return to fundamentalism? David Report, 13. http://static.davidreport.com/2011/04/dr_2011_13_1.pdf

Cassidy, T. (2018). Research approaches for culturally significant design. In S. Walker, M. Evans, T. Cassidy, J. Jung, J., \& A. T. Holroyd (Eds.), Design roots: Culturally significant designs, products and practices (pp. 277-289). Bloomsbury Academic.

Coulson, D., \& Campbell, A. (2001). African rock art: Paintings and engravings on stone. Harry N. Abrams.

Cunningham, A. B., \& Terry, M. E. (2006). African basketry: Grassroot art from Southern Africa. Fernwood Press.

Daniels, D. (2011). Decolonising the researcher's mind about southern research: Reflections from the field. Stellenbosch University.

Fletcher, K. (2008). Sustainable fashion and textiles: Design journey. Earthscan.

Forssman, T., \& Gutteridge, L. (2012). Bushman rock art: An interpretive guide. Southbound.

Haverkamp, M. (2013). Synesthetic design: Handbook for a multi-sensory approach. Birkhäuser.

Hemmings, J. (2013). Postcolonial textiles: Negotiating dialogue. In J. Gohrisch \& E. Grünkemeier (Eds.), Postcolonial studies across the disciplines (pp. 23-50). Rodopi.

Hemmings, J. (2015). Cultural threads: Transnational textiles today. Bloomsbury Academic.

Jansen, A. (2019). Decolonising fashion. Defying the 'white man's gaze'. http://vestoj.com/ category/opinion/

Kolko, J. (2012). Wicked problems: Problems worth solving: A handbook \& a call to action. Austin Center for Design.

Kuure, E., Pietarinen, H., \& Vanhanen, H. (2016). Experimenting with arctic social phenomena: A multicultural workshop model. In T. Jokela \& G. Coutts (Eds.), Relate north: Culture community and communication (pp. 104-129). Lapland University Press.

Mäkiranta, M., \& Timonen, E. (2015). Abstrakti materiaalisuus [Abstract materiality]. Ruukku: Studies in Artistic Research, 3.

Malan, J. S. (1998). Die Voelker Namibias (F. R. Kuno, Trans.). Klaus Hess.

McBrinn, J. (2017). Migrations, national college of art and design, Dublin, Ireland April 30May 29, 2015. Textile, 15(1), 112-117.

McIntyre, A. (2008). Participatory action research. SAGE Publishing.

NASCO. (2019). Roots of the first tree: A landmark exhibition of contemporary Namibian San art. National Art Gallery of Namibia, Windhoek, August 29 to September, 2019. www.nacso. org.na/event $/ 2026$

Nimkulrat, N. (2009). Paperness: Expressive material in textile art from an artist's viewpoint. University of Art and Design Helsinki. 


\section{Heidi Pietarinen and Eija Timonen}

Omba Arts Trust. (2020, June 4). www.facebook.com/OmbaArtsTrust/

PARTY.(2017).www.ulapland.fi/InEnglish/Units/Faculty-of-Art-and-Design/Research-Development/ Ongoing-Projects/PARTY

Pietarinen, H. (2018). Sirocco jacquard textile. www.ulapland.fi/EN/Art-and-Design/Artby-our-staff/Heidi-Pietarinen

Räsänen, M. (2015). Visuaalisen kulttuurin monilukukirja [A multi-reading book on visual culture.]. Aalto University School of Art and Design.

Ridanpää, J. (2019). Postcolonial critique and the north in geographical imaginations. In M. Mäkikalli, Y. Holt, \& T. Hautala-Hirvioja (Eds.), North as a meaning in design and art (pp. 123-137). Lapland University Press.

Rihlama, S. (1997). Värioppi. Rakennustieto.

le Roux, K. (1993). Rural art in Namibia. The Rössing Foundation.

le Roux, K. (2004). Voices of the San: Living in southern Africa today. Kwela Books.

le Roux, K. (2014a). Martha Kavantjindje: In Namibia: A land of memories and more (pp. 86-89). Fabrica.

le Roux, K. (2014b). Martha Uxama: In Namibia: A land of memories and more (pp. 276-277). Fabrica.

Sarantou, M. (2014). Namibian narratives: Postcolonial identities in craft and design [Doctoral dissertation, Visual Arts, School for Art, Architecture and Design, Division: Education, Arts and Social Sciences, University of South Australia]. http://search.ror.unisa.edu.au/media/ researcharchive/open/9915908588001831/53108220130001831

Schlein, A., \& Ziek, B. (2006). The woven pixel: Designing for jacquard and dobby looms using photoshop. Bridgewater Press.

Selby, M. (2011). Color and texture in weaving: 150 contemporary designs (1st ed. for North America). Interweave; Manning Partnership [distributor].

Sheehan, N. W. (2011). Indigenous knowledge and respectful design: An evidence-based approach. Design Issues, 27(4), 68-80.

Shineshine. (2017). Shineshine. www.shineshine.co.za

Shoup, J. A. (2011). Ethnic groups of Africa and the Middle East: An encyclopedia (pp. 235236). ABC-CLIO.

Siukonen, J. (2011). Vasara ja hiljaisuus. Lybyt johdatus työkalujen filosofiaan [Hammer and silence: A brief introduction to the philosophy of tools]. Academy of Fine Arts.

Smith, H., \& Dean, R. T. (2009). Practice-led research, research-led practice in the creative arts. Edinburgh University Press.

Smith, R. C., Winschiers-Theophilus, H., Kambunga, A. P., \& Krishnamurthy, S. (2020, June). Decolonizing participatory design: Memory making in Namibia. Proceedings of the 16th Participatory Design Conference 2020-Participation (s) Otherwise-Volume 1 (pp. 96-106).

Timonen, E. (2018). The light of ice. www.lightofice.net

Timonen, E. (2019). Icephery and the icy score: Concepts for a multisensory approach. Ruukku, 14. www.researchcatalogue.net/view/631016/631017

Tunstall, D. (2013). Design anthropology: Theory and practice. In W. Gunn, O. Ton, \& R. C. Smith (Eds.), Decolonizing design innovation: Design anthropology, critical anthropology, and indigenous knowledge (pp. 232-250). Bloomsbury Academic.

Tunstall, D. (2019, November 11). Design anthropologist Dori Tunstall on decolonizing design. UC Berkeley. https://news.berkeley.edu/2019/01/25/berkeley-talks-dori-tunstall/

UNESCO. (n.d.). What is intangible cultural heritage? www.unesco.org/culture/ich/en/ what-is-intangible-heritage-00003

Vaughan, L. (2017). Practice-based design research. Bloomsbury Academic.

Walker, S., Evans, M., Cassidy, T., Jung, J., \& Holroyd, A. T. (2018). Design roots: Culturally significant designs, products and practices. Bloomsbury Academic.

Wood Conroy, D. (1997). Alexander Ian Arcus: Walls and Pathways. http://www.alexander arcus.com.au/assets_d/45347/download_media/dwc_wallsandpathwaysessay_37kb_132.pdf 